\title{
AS DISPOSIÇÕES PEDAGÓGICAS EM CURSOS DE FORMAÇÃO INICIAL E CONTINUADA: UM ESTUDO DE CASO SOBRE O PROJETO PRIMEIRO PASSO - JOVEM APRENDIZ
}

\author{
Prof. Ms. Leonardo Araújo Lima* \\ Prof. Dr. Francisco Horácio Frota da Silva Frota***
}

Resumo: As demandas por trabalho qualificado nas atividades produtivas e de serviço demarcam a educação profissional como estratégia de desenvolvimento econômico e social para o Estado brasileiro. Este artigo trata sobre as perspectivas pedagógicas das políticas públicas de educação profissional, mais especificamente aquelas políticas em nível de formação inicial e continuada de trabalhadores. Propomos a análise desta questão através de revisão conceitual sobre as bases liberais da educação para o trabalho, além de análise contextual e empírica. Para esta última escolhemos um estudo de caso junto ao Projeto Primeiro Passo - Jovem Aprendiz, uma ação profissionalizante do Governo do Estado do Ceará.

Palavras-chave: Educação profissional, políticas públicas e perspectivas pedagógicas.

Abstract: The demand for skilled labor in productive activities and service demarcate professional education as an economic and social development strategy for the brazilian state This article discusses the pedagogical perspectives of public policies of education, specifically those policies at the level of initial and continuing training of workers. We propose to address this issue through conceptual review of the liberal foundations of education for work, and contextual and empirical analysis. For the latter chose a case study by the Projeto Primeiro Passo - Jovem Aprendiz, a vocational action of the government of the state of Ceará.

Keywords: Education to professional , public policy and pedagogical perspectives 
(*) Graduação em Psicologia pela Universidade Federal do Ceará (2007); mestrado em Planejamento e Políticas Públicas pela Universidade Estadual do Ceará (2013).

(**) Graduação em Ciências Sociais pela Universidade de Fortaleza (1978); mestrado em Educação pela Universidade Federal do Ceará (1992); e doutorado em Sociologia - Universidad de Salamanca (1998).

\section{AS POLTICAS PÚBLICAS DE EDUCAÇÃO PRA O TRABALHO}

A necessidade por adaptação aos preceitos da qualificação profissional aparece como urgente aos trabalhadores que buscam inserção ou prosperidade no mercado de trabalho, principalmente daqueles mais jovens com menos experiências e menos tempo de formação. $\mathrm{O}$ aprendizado de habilidades e conhecimentos específicos se mantém como via de acesso às oportunidades de trabalho. Na medida em que as exigências por qualificação atingem a sociedade em geral, surgem demandas por estratégias do Estado com fins de fomento ao trabalho e renda para a população.

As políticas públicas de educação profissional constituem tema central para este estudo. Abordar tal temática envolve a discussão de questões como: quais são os fundamentos destas políticas? Qual é o contexto político e econômico de sua formulação? Qual é o histórico destas ações no Brasil? A quem realmente servem e como são realizadas?

Neste artigo temos como objetivo compreender acerca as perspectivas pedagógicas das políticas públicas brasileiras que envolvem educação profissional. Tais perspectivas pedagógicas são abordadas no sentido de fundamentação pragmática e objetivo final. $\mathrm{Na}$ medida em que o estudo sobre as políticas públicas de educação profissional consistem num tema abrangente, já que deveríamos aí considerar todos os cursos financiados pelo poder público e voltados para inserção produtiva (cursos em níveis de formação inicial e continuada, técnico e tecnológico), reforçamos aqui a especificação do nosso estudo para as ações governamentais que envolvam cursos profissionalizantes em nível de formação inicial e continuada - um dos três indicados no Decreto Federal no 5.154, de 23 de julho de 2004. Elaboramos o estudo da questão a partir de três enfoques: teórico, contextual e empírico.

A análise teórica acerca as diferentes perspectivas pedagógicas da educação em termos de objetivos finais se efetiva tomando como base as influências da 
ideologia liberal (de valorização da razão humana e da liberdade individual) nas concepções de educação voltada para o trabalho. Direcionamos nossa abordagem conceitual na busca por investigar pressupostos teóricos que possuem influência na formulação conceitual das atuais políticas públicas de educação profissional, no Brasil e no mundo. Sendo assim fazemos um esboço de tais contribuições a partir de diferentes autores obedecendo a uma sequencia cronológica desde o Iluminismo do século XVII (John Locke, Dennis Condorcert, August Comte), passando pelas contribuições do modelo produtivo taylorista-fordista (Winslow Taylor e Henry Ford), pelas expectativas da Teoria Crítica (Max Horkheimer, Theodor Adorno e Jürgen Habermas), até chegar aos aspectos da nova morfologia do trabalho emergente na segunda metade do século XX (Robert Castel, Ricardo Antunes e Henrique Nardi). A partir deste resgate conceitual destacamos uma leitura categorial que considera a existência de dois pressupostos pedagógicos fundamentais, as quais neste estudo denominamos de instrumental-funcionalista e humanista-emancipatória.

A análise contextual do tema abordado inicia-se concomitante à sua apreensão teórica quando propomos a verificação sobre o histórico de acontecimentos econômicos e políticos que marcam as transformações do sistema produtivo dominante no último século. Tais transformações são acompanhadas pelo formato de organização da educação aplicada às demandas do mundo do trabalho. A compreensão histórica acerca a organização do trabalho numa economia capitalista, na qual as diretrizes liberais de acumulação, livre concorrência e flexibilização nas contratações de pessoal, reforçam ainda mais o reconhecimento da educação profissional como fator de entrada e permanência no mercado de trabalho.

Como a questão estudada está vinculada à análise da consolidação regulamentarda política pública de educação profissional no Brasil, nossa contextualização passa ainda pela apresentação das principais medidas realizadas pelo Estado brasileiro no sentido de consolidar ações de profissionalização como estratégia de desenvolvimento. Neste sentido resgatamos os principais acontecimentos na segunda metade do século XX que marcam a entrada da educação profissional na pauta legislativa e executiva do governo brasileiro. 
A abordagem empírica acerca a questão abordada acontece por meio de um estudo de caso que busca compreender como se efetiva na prática a dualidade de perspectivas pedagógicas nas diretrizes regulamentares e execução do Projeto Primeiro Passo - Jovem Aprendiz. Este projeto caracteriza-se por ser executado pelo Governo do Estado do Ceará através da Secretaria do Trabalho e Desenvolvimento Social (STDS), possuir abrangência em todas as oito macrorregiões administrativas do estado, realiza educação profissional em nível de formação inicial e continuada de trabalhadores, além de ser regulamentado pelas diretrizes da Lei da Aprendizagem (Lei 10.097, de 19 de dezembro de 2000) e de portarias do Ministério do Trabalho e Emprego (MTE).

\section{AS BASES LIBERAIS DA EDUCAÇÃO PARA O TRABALHO}

Iniciamos a discussão conceitual sobre educação profissional, ou educação para o trabalho, resgatando inicialmente fundamentos teóricos alinhados ao pensamento iluminista de valorização da razão humana como mecanismo de progresso social e econômico. A consolidação dos valores liberais burgueses durante o século XVIII contribuiu para geração de conhecimentos e suas aplicações no âmbito político e produtivo da sociedade. Observamos, então, que a partir deste período existe uma maior integração entre as práticas educativas e as atividades de trabalho.

A proposta pelo corte histórico na análise dos conceitos de educação para o trabalho a partir do Iluminismo segue a proposta de Werner Markert (1994), pesquisador de origem alemã que muito contribuiu com teorias e métodos de intervenção na área de educação profissional, principalmente na Alemanha e no Brasil. Apesar de nosso estudo não se limitar estritamente a análise das contribuições do referido autor, iremos utilizar seus argumentos teóricos por compreender que suas obras nos trazem um rico aparato de fundamentos para o objetivo deste artigo.

Markert defende ser no movimento ideológico do Iluminismo que acontece a "reivindicação antifeudal, burguesa e revolucionária, por um desenvolvimento omnilateral* da capacidade humana" (MARKERT, 1994, p. 9). Portanto é neste contexto que podemos identificar o início (ou o resgate na filosofia 
clássica) de uma perspectiva teórica moderna que vislumbra a autonomia do sujeito a partir da valorização da razão humana. Markert considera Jonh Locke como um dos primeiros autores modernos que se propõe a relacionar o conceito de educação com a sociedade e a política. Para Locke seria necessária a construção de um modelo educacional voltado para cidadãos, que para ele eram apenas os sujeitos com propriedade privada e que pagam impostos, no intuito de desenvolver habilidades burguesas que garantam a permanência e administração de suas posses. Torna-se aqui menos importante o acúmulo de conhecimentos filosófico e científico, tomando maior destaque conhecimentos de proveito prático vinculado a uma razão instrumental necessária ao homem de negócios: “o erudito é, para o progresso social, menos importante que o cidadão virtuoso, e também administrativamente produtivo" (LOCKE apud MARKERT, 1994, p. 21).

(*) O conceito de omnilateralidade foi desenvolvido por Marx quando se referia à compreensão do homem em sua totalidade. A formação educacional deveria ter o papel de formar o sujeito como um ser integral, considerando os diferentes âmbitos de sua existência e convivência.

Há ainda autores que, em paralelo ao trabalho de Locke, reforçaram nas utopias sócio-revolucionárias iluministas concepções de educação aplicáveis à dinâmica do progresso burguês e industrial que indiquem para o desenvolvimento de uma sociedade mais harmoniosa. Destacam-se aqui as contribuições dos franceses Denis Condocert, Conde de Saint Simon e Augusto Comte. Condorcert desenvolve um programa otimista em relação ao progresso industrial que vislumbra uma educação geral correspondente ao progresso social com fins no nivelamento da diferenciação de classes: "isto representaria um meio de atenuar a desigualdade resultante da diferença de posses, de mesclar as classes que essa diferença pretende separar” (MARKERT, 1994, p. 25). Em caráter divergente às pretensões de Condocert, mas ainda vinculado à valorização da razão humana instrumental para produção industrial, Saint Simon desenvolve uma teoria contra as camadas “ociosas" no período político pósrevolucionário francês sob o comando de Napoleão. Para Saint Simon as diferenças sociais seguiriam a lógica das capacidades produtivas e "quando a hierarquia social se estrutura como hierarquia de capacidades, o fenômeno da divisão de trabalho perde seu aspecto alienador” (MARKERT, 1994, p. 30). Sendo assim, na ordem social 
vigente cada um seria classificado segundo suas aptidões e remunerado segundo o que produzia.

O progresso do sistema econômico burguesa aliado ao avanço racional científico no século XIX levou Augusto Comte a formular a teoria do positivismo. Esta se vincula à observação de que a ciência pode penetrar nas esferas da vida humana e natural de modo a prever seus movimentos e controlá-las a fim de garantir uma estabilidade do sistema social harmônico. A educação na teoria de Comte não teria como meta a individualidade (possibilidade de emancipação humana), mas pode ser entendida essencialmente como "difusão geral das disciplinas positivas mais importantes para execução do trabalho" (Comte apud MARKERT, 1994, p. 33). No entanto identifica-se em tais prerrogativas a justificativa pelo real interesse da educação baseada no positivismo: o disciplinamento da população, camuflando assim a realidade alienante vivenciada pelo trabalho manual. A ordem positiva de Comte representa o primado da dominação do conhecimento econômico e político sobre a população trabalhadora.

\section{A DISCIPLINA NO MODELO DE PRODUÇÃO TAYLORISTA - FORDISTA}

A base da Revolução Industrial, no início do século XIX, está associada à efetivação do movimento iluminista de valorização da razão e à aplicação das tecnologias emergentes no âmbito da produção fabril. Os ideais iluministas avançam para construção de uma pedagogia que ao enaltecer o potencial racional do homem lhe concede argumentos para validação da autonomia individual como forma de desenvolvimento integral do sujeito. No entanto tal sentido emancipatório do conhecimento burguês iluminista não encontrou vinculação prática perante à realidade imposta pelo avanço do modelo industrial de produção, o qual determinava a reprodução de práticas disciplinares e alienadoras.

Esta pragmática pode ser evidenciada quando Frederick Winslow Taylor (1856-1915), chamado de "pai da administração científica”, a partir das obras Princípios de administração científica (1911) e Shop management (1910), preconizou a 
divisão técnica do trabalho humano dentro da produção industrial, cuja meta assentava na busca por tornar o processo produtivo mais ágil pela subdivisão de funções, tanto na produção, como na administração. Este processo permitiria que cada funcionário cumprisse as tarefas que lhe foram designadas, com o mínimo de conhecimentos. $\mathrm{Na}$ lógica taylorista, toda a complexa análise e planejamento do sistema produtivo ficam a cargo particular do sistema administrativo. $\mathrm{Na}$ mesma direção lógica encontramos as práticas administrativas de Henry Ford (1841-1925), o qual fez uso da concepção taylorista como base para construção da linha de montagem em sua indústria de automóveis.

Neste período os programas de educação para população em geral cristalizam-se na escola primária, a qual promovia a socialização dos indivíduos ensinando apenas conhecimentos básicos para convivência social. A educação para o trabalho estava totalmente fora da esfera de ação da instituição escolar, e era especialmente influenciada pela estrutura produtiva de tipo taylorista-fordista. Neste modelo de produção não há necessidade, salvo exceções, de conhecimentos específicos para a contratação e exercício do trabalho nas linhas de produção. Os conhecimentos detidos pelos trabalhadores eram desconsiderados enquanto competências. As pessoas deveriam ser submetidas à nova disciplina da fábrica, que passava a ser organizada dentro dos métodos disciplinares. Para isso deveriam ser educados de forma a admitir os novos processos como superiores aos antigos, numa estratégia de "lavagem cerebral", para colocar através do treinamento os novos fins e novas rotinas. Se antes da revolução industrial a educação da força de trabalho era de competência dos pares, ou seja, entre colegas trabalhadores, passava agora a ser organizada pela gerência que estipulava as novas rotinas e o treinamento para a aquisição das competências para seu desempenho. A nova educação, ou adestramento, correspondia com o objetivo de retirar dos trabalhadores a capacidade de controle de sua força produtiva. Todo controle migrava para as mãos da gerência científica.

O advento técnico e científico desenvolvido nas linhas de produção da grande indústria exerceu crescente influência sobre a formação educativa desejável para a "sociedade salarial" (Castel 2010) Neste sentido o exercício do trabalho manual 
no modelo taylorista-fordista de produção passou a ser reforçado por uma pedagogia disciplinar nos termos de organização do modo de vida dos trabalhadores (ideologias, horários, aspirações políticas e econômicas).

\section{CONTRIBUIÇÕES DA TEORIA CRÍTICA PARA O CONCEITO DE EDUCAÇÃO}

A influência ideológica fomentada pelos ideais iluministas no âmbito político e econômico permaneceram como argumentos de legitimação do poder instituído pelo modo de trabalho e produção industrial. A valorização da razão humana como meio de progresso social e geração de riquezas constitui-se como um primado cultural com influência nos mais diversos setores da vida humana em sociedade, e a educação assume assim destaque por constituir um mecanismo eficaz de disciplina. A dominação ideológica do capitalismo, para além do sistema econômico, atinge a dimensão formativa do sujeito social, aquele que deveria se adaptar aos mecanismos de trabalho.

O formato das vinculações contratuais para produção de mercadorias e manutenção da sobrevivência passa agora, e cada vez mais intensamente, pelo modelo industrial de contratações. Diante tal quadro de dominação ficou difícil a penetração de ideais iluministas que valorizavam a formação integral do homem, uma pedagogia para o desenvolvimento omnilateral era divergente, se não contrária, aos preceitos de razão instrumental defendidos pelos ditames da grande indústria. Em nenhum Estado Nação europeu a classe trabalhadora foi respeitada conforme os padrões imaginados pelo Iluminismo. O que prevaleceu foi um sistema capitalista exploratório com todos seus aspectos de manipulação da força de trabalho e "adestramento" instrumental.

Como é sabido, para toda estrutura de poder existe uma resistência. Tal cenário estrutural e subjetivo da sociedade dá cabimento para a crítica de Karl Marx sobre os sistemas produtivos vigentes no final do século XIX. Entre outras análises, Marx propõe uma revisão da compreensão sobre o conceito de sujeito, atribuindo-lhe uma correlação existencial com a sociedade numa dialética materialista e histórica. "A prática social, como modo de produção histórico-concreto, significa a base/estrutura, 
que abrange todos os setores da vida" (MARX 1982, p.73).Sendo assim, as ideias de Marx convergem para compreensão de um sujeito com determinações universalistas, o qual percorre um constante processo de apropriações e internalizações com o mundo a sua volta no sentido de concretizar sua existência.

As contribuições de Karl Marx para constituição do método de pesquisa baseado na materialismo histórico e dialético influenciaram, para além do movimento político socialista, diversos estudos nas áreas da Sociologia, Pedagogia, Psicologia, etc, durante o século XX. Chegando a década de 1920 surge em Frankfurt um movimento científico que reintroduz a condição de emancipação humana encontrada nas teorias iluministas, agregando a isto as novas dimensões de análise provenientes do método dialético de Marx. Este movimento se concretiza na execução de pesquisas interdisciplinares acerca a condição humana. Trata-se de uma mobilização acadêmica em resistência à instrumentalização do capitalismo funcionalista e o irracionalismo nacionalista dos regimes totalitários em ascensão durante este período histórico, tratase da Teoria Crítica da Formação do Homem. Para uma elucidação sobre as influências da Teoria Crítica no âmbito da educação seguimos novamentea recomendação teórica de Werner Markert ao destacar três autores expoentes:

\begin{abstract}
$\mathrm{Na}$ explanação, o ponto de partida da pesquisa de Max Horkheimer, que queria salvar, mediante uma pesquisa social interdisciplinar, a abrangente reivindicação de validade e interpretação do Iluminismo contra a razão instrumental tanto das novas ciência positivas (...); a insistência de Adorno na autonomia do sujeito em oposição aos mecanismos de manipulação da indústria cultural (...); por fim a teoria de Habermas, que estabelece uma analogia de significado da implícita exigência de razão na ação comunicativa com a reconstrução do materialismo histórico, a fim de poder expressar analiticamente e com mais clareza as dimensões objetivas e subjetivas das tendências de universalização na modernidade. (MARKERT, 1994, p. 72).
\end{abstract}

No objetivo de demonstrar apenas algumas ideias dos autores mencionados destacamos que Adorno aponta para uma concepção de educação voltada para autonomia do sujeito. Ele esperava que a pedagogia democrática, a educação política refletida filosoficamente e sociologicamente, diminuísse os mecanismos de resistência e superasse a "semicultura" instaurada pelo poderio nacionalista, tornando possível o fortalecimento da autonomia do sujeito. 
Cumulativamente às ideias de Adorno, Habermas propõe uma reconstrução da Teoria Crítica já na segunda metade do século XX. Na proposição deste autor existe uma associação entre as tendências produtivas do capitalismo com uma teoria geral da ação comunicativa, proveniente das constatações acerca o mercado de trabalho cada vez mais dependente das habilidades argumentativas individuais e menos da força de trabalho manual. Como reação aos mecanismos de dominação subjetiva vigente, Habermas propõe a construção categórica de um conceito educacional integral, o qual considere a mediação dialética entre a teoria, a política e a prática educativa perante o princípio universalista nos processos de socialização do sujeito. Neste sentido a educação responde aos objetivos de qualificação individual e, ao mesmo tempo, um meio para emancipação intelectual e política.

\section{A NOVA MORFOLOGIA DO TRABALHO E SUAS IMPLICAÇÕES PARA EDUCAÇÃO PROFISSIONAL}

O modelo de produção taylorista perde ênfase a partir da segunda metade do século XX e surgem novos modelos de gestão baseados na flexibilidade da produção e contratação de pessoal. Este quadro econômico é caracterizado por medidas condizentes ao programa neoliberal com fins de restabelecer o crescimento do capitalismo e, no âmbito do mercado de trabalho, devemos atentar para o fenômeno da reestruturação produtiva. "A reestruturação produtiva pode ser definida como a transformação do modelo de acumulação taylorista-fordista no contexto do estado-nação para a acumulação flexível no contexto da globalização” (NARDI, 2006, p. 53).

Neste sentido, aliados à tecnologia e sua consequente utilização para substituir a mão de obra humana - gerando uma verdadeira "limpeza" nas linhas de produção - destacam-se fenômenos como a flexibilização dos contratos de trabalho (mudanças nas normas de compra e venda da mão de obra fomentando a informalidade) e a precarização das condições de trabalho (situações adversas de execução do serviço) como realidades contingentes de uma nova morfologia do trabalho (Antunes, 2005). As formas de filiação do empregado passam por mudanças, 
o trabalhador fica mais inseguro quanto sua vinculação e passa a buscar por métodos individuais de aprimoramento e concorrência.

Esta "nova” morfologia do trabalho é, portanto, a base realística para o presente estudo. $\mathrm{O}$ desemprego estrutural consiste num dos principais entraves para $\mathrm{O}$ acesso às oportunidades de educação, cultura, consumo, saúde, entre outros. A renda por meio do trabalho parece ser a única chance que o cidadão encontra para garantir sua qualidade de sobrevivência, e isso se complica num quadro de restrição do emprego formal. A realidade da concorrência pelas oportunidades de colocação no mercado marca novamente o surgimento de discursos que enaltecem a educação profissional como mecanismo de garantia para inserção..

A educação profissional no contexto do mercado de trabalho flexível se volta para atividades mais intelectualizadas, direcionadas para a manipulação de máquinas, manutenção, organização do sistema produtivo, monitoramento de riscos, entre outros. Além disso, desenvolvem-se nos setores administrativos atividades vinculadas às funções de planejamento, projetos, recursos humanos e comercialização. O quadro de demandas para o trabalho nas indústrias se diversifica na mesma amplitude e rapidez com que a tecnologia é integrada ao sistema produtivo. A educação profissional acompanha, portanto, esta dinâmica de modernização e diversificação, passando a ser considerada até como condição para o desenvolvimento de parques industriais.

Diante a percepção que o nível de crescimento da indústria estava não apenas no seu potencial tecnológico agregado às máquinas, mas sim também na capacidade produtiva e inovadora de seu quadro de funcionários, o sujeito trabalhador assume um papel mais preponderante dentre as prioridades da organização. Neste novo modelo de organização sistêmicaa produção e serviços das empresas modernas identifica-se uma mudança no status do trabalhador e na sua consciência tradicional. Tal perspectiva de aproximação da realidade laboral com os valores humanos incute na compreensão de que "o trabalhador precisa de sua competência profissional, mas também de sua competência individual, a qual possibilita sua participação consciente no trabalho e na sua vida política e cultural” (MARKERT, 2004, p. 128). As influências 
deste novo modelo de trabalhador no âmbito da educação profissional denotam que os objetivos de uma aprendizagem para o novo mercado de trabalho devem ter uma relação com as formas interativas de comunicação no trabalho e na vida, de forma que as competências instrumental e comunicativa tenham uma melhor interligação com a prática educativa.

\section{A DUALIDADE DE PERSPECTIVAS PEDAGÓGICAS}

Até agora neste artigo nos detivemos no interesse de apresentar as principais fundamentações para a prática da educação a partir dos princípios liberalistas. Fizemos isso obedecendo a uma sequencia cronológica desde o Iluminismo do século XVII até os aspectos da nova morfologia do trabalho emergente na segunda metade do século XX. Tal apreensão nos é importante para que a partir daí possamos identificar as principais tendências conceituais da educação voltada para o trabalho na evolução do pensamento moderno.

Analisando as contribuições apresentadas verificamos uma dualidade de pressupostos educacionais que, embora não necessariamente se excluam e estejam ancoradas no mesmo fundamento de primazia da razão humana, indicam concepções distintas do indivíduo em relação ao trabalho e sociedade. De um lado, um primeiro pressuposto pode ser descrito em termos mais instrumentais e funcionalistas, que observam na educação um instrumento disciplinar, mecânico e racionalista. A educação tem aqui o papel de capacitar e tornar produtivos os indivíduos para composição de trabalhadores que melhor se adaptem às condições e exigências do sistema produtivo dominante. De outro lado, um segundo pressuposto se fundamenta na educação como meio de emancipação do indivíduo, dotando-o de capacidade racional crítica que permita seu melhor posicionamento político e profissional no percurso de sua inclusão, cidadania e transformação ao ambiente social. Se faz referência aqui a uma visão mais tradicional acerca princípios da ação humana conforme o liberalismo iluminista, bem como às perspectivas sobre educação encontradas na Teoria Critica. 
QUADRO I - Fundamentos conceituais das perspectivas pedagógicas identificadas

\begin{tabular}{|c|c|}
\hline Tendência Educacional & Base Teórica \\
\hline Funcionalista e Instrumental & $\begin{array}{l}\text { * Educação com o intuito de desenvolver habilidades burguesas de } \\
\text { Jonk Locke; } \\
\text { * Educação como a totalidade dos esforços empreendidos para } \\
\text { adequar toda nova geração à ordem social de Saint Simon; } \\
\text { * Positivismo de Augusto Comte ao afirmar que a educação não } \\
\text { teria como meta a individualidade, mas sim a difusão geral das } \\
\text { disciplinas positivas mais importantes para o progresso econômico } \\
\text { e social } \\
\text { * Princípios administrativos de W. Taylor e H. Ford onde } \\
\text { prevalecem a premissa do trabalho operário repetitivo, não } \\
\text { especializado e disciplinado para produção industrial em massa. }\end{array}$ \\
\hline Humanista e Emancipatória & $\begin{array}{l}\text { * Princípios da liberdade individuale razão humana do Liberalismo; } \\
\text { * Movimento humanista baseado em teorias marxistas sobre o } \\
\text { processo de desenvolvimento do sujeito em relação ao seu contexto } \\
\text { social e histórico, a Teoria Crítica da Formação do Homem, onde } \\
\text { destaca-se: } \\
\text { - A educação como um meio para a autonomia de Theodor } \\
\text { Adorno; } \\
\text { - A construção categórica de um conceito educacional integral de } \\
\text { Jürgen Hebermans; } \\
* \text { Argumentos gerenciais de valorização das competências } \\
\text { individuais nas empresas a partir da reestruturação produtiva. }\end{array}$ \\
\hline
\end{tabular}

Fonte: Elaboração própria do autor

\section{CONTEXTO ECONÔMICO E POLÍTICO DE INSTITUCIONALIZAÇÃO DAS POLÍTICAS PÚBLICAS DE EDUCAÇÃO PROFISSIONAL NO BRASIL}

$\mathrm{Na}$ década de 80 , diante do agravamento da crise internacional do capitalismo que já se estendida no panorama internacional desde o início da década de 60, a economia brasileira entra em extraordinária recessão, com aspectos problemáticos expressos no aumento da dívida externa, na expansão das práticas neoliberais de privatizações e desemprego, no "desassalariamento" das ocupações, nos baixos investimentos em infraestrutura e inovação tecnológica, e ainda, para piorar, no crescimento da população que necessitava ser amparada pelas políticas assistenciais.

Diante o cenário de risco social e instabilidade política nascem pressões populares por uma Reforma Constituinte, pois a Constituição em vigor ainda representava padrões tradicionalistas do poder militar que governou o país por mais 
de 30 anos. É interessante perceber que a aproximação desta constituição com os valores liberalistas podem ser identificados ainda no preâmbulo, quando se estabelece como objetivos “(...) instituir um Estado Democrático destinado a assegurar o exercício dos direitos sociais e individuais, a liberdade, (...), a igualdade e a justiça como valores supremos de uma sociedade fraterna (...)”. (CF 1988, preâmbulo).

A Constituição Federal de 1988 é um marco para determinação da educação como um direito social: "são direitos sociais a educação, a saúde, a alimentação, o trabalho, a moradia, o lazer, a segurança, a previdência social (...)" (CF 1988, Artigo 6). A Constituição Federal de 1988 estabelece também que "a educação, direito de todos e dever do Estado e da família, será promovida e incentivada com a colaboração da sociedade, visando ao pleno desenvolvimento da pessoa, seu preparo para o exercício da cidadania e sua qualificação para o trabalho." (CF 1988, Artigo 205).

Observamos que no texto da Constituição quando trata de educação existem referências aos princípios encontrados nas duas perspectivas pedagógicas abordadas conceitualmente no início do artigo, ou seja, a coexistências de tendências liberalistas de cidadania e emancipação humana, por um lado, bem como produtividade e uso instrumental da inteligência, por outro. Percebe-se também esta dualidade quando é revelado o papel da educação parapromover o pleno desenvolvimento do indivíduo e sua qualificação para o trabalho.

Já em 1996 acontece a promulgação da Lei de Diretrizes e Bases da Educação Nacional (LDBEN - Lei $n^{\circ}$ 9.394, de 20 de dezembro de 1996- Lei Complementar prevista no Artigo 214 da Constituição Federal de 1988), quando a educação profissional é regulamentada (artigos 37, 38 e 39) e passou a ter identidade própria, pois até então esteve agregada ao ensino de $2^{\circ}$ grau (atual ensino médio). Segundo o texto desta Lei, a característica marcante da educação profissional é a sua capacidade de integrar-se "às diferentes formas de educação, ao trabalho, à ciência e à tecnologia (...), com vistas a conduzir o educando ao permanente desenvolvimento de aptidões para a vida produtiva" (LDBEN, art. 39). 
No período posterior à promulgação da LDBEN uma série de instrumentos normativos provenientes do Poder Executivo restringiram a oferta de ensino médio e técnico ou a expansão da rede federal de educação profissional. Tais medidas tornaram-se alvo de críticas por parte de entidades científicas, órgãos políticos representativos dos trabalhadores, professores e intelectuais. Os resultados desses eventos apontaram, dentre outras demandas, para necessidade de revogar os instrumentos normativos da educação profissional, pois representavam um retrocesso na esfera educacional. Sendo assim, no ano de 2004 é promulgado pelo Presidente Luís Inácio Lula da Silva o Decreto Federal n ${ }^{\circ}$ 5.154, de 23 de julho de 2004, este instrumento modifica e revoga o Decreton $^{\circ}$ 2.208, de 17 de abril de 1997, que regulamentava os artigos 36, 37, 38 e 39 da LDBEN, estabelecendo então novas determinações concernentes à educação profissional.

O novo dispositivo trata de reforçar o caráter específico da educação profissional e a diferencia do ensino médio. O Decreto $\mathrm{n}^{\circ} 5.154$ permitiu ainda a oferta da modalidade de ensino médio integrado ao ensino técnico. É importante também salientar que este novo Decreto renomeou os três níveis de classificação no que se refere à educação profissional: I- formação inicial e continuada de trabalhadores; II - educação profissional técnica de nível médio; e III - educação profissional tecnológica de graduação e de pós-graduação. $O$ que basicamente diferencia estes três níveis de educação profissional consiste na quantidade de carga horária dos cursos e a escolaridade prévia mínima exigida.

Para o estudo da questão neste artigo nos concentraremos na análise das regulamentações relacionadas ao nível de formação inicial e continuada de trabalhadores, o nível mais básico de formação profissional, com menos carga horária de período letivo, além de maior abrangência devido à simples exigência prévia de conclusão do ensino fundamental escolar. Dessa forma, seguiremos com a discussão proposta pelo artigo a partir do estudo de caso sobre as perspectivas educacionais presentes na execução de uma política pública de formação inicial e continuada de trabalhadores no âmbito do Governo do Estado do Ceará. 


\section{ESTUDO DE CASO SOBRE O PROJETO PRIMEIRO PASSO - JOVEM}

APRENDIZ

A abordagem empírica sobre as perspectivas pedagógicas políticas públicas de educação profissional em nível de formação inicial e continuada é aqui apresentada como estudo de caso realizado junto à execução do Projeto Primeiro Passo - Linha Jovem Aprendiz, uma ação profissionalizante do Governo do Estado do Ceará através da Secretaria do Trabalho e Desenvolvimento Social (STDS/CE).

Escolhemos pelo Projeto Primeiro Passo - Jovem Aprendiz devido ao fato de que consiste numa ação com mais de sete anos em execução, possui abrangência territorial em todas as oito macrorregiões administrativas do Ceará (prioritariamente nos municípios com maior potencial de desenvolvimento econômico), além disso, apesar de ser executado por órgão do governo estadual, é regulamentado por diretrizes da Lei da Aprendizagem (Lei Federal No 10.097, de 19 de dezembro de 2000). Acreditamos que este enfoque nos agrega validade para as análises empíricas acerca o formato das políticas públicas de educação profissional no Ceará, especificamente dentre os cursos de formação inicial e continuada de trabalhadores.

Para compreensão acerca as perspectivas pedagógicas imanentes à execução física do projeto Primeiro Passo - Jovem Aprendiz nossa abordagem empírica utiliza como fontes de evidências: documentos, registros de arquivo e entrevistas. O Quadro II demonstra sobre as evidências e processo de coleta dos dados.

Quadro II - Fontes de evidências e processo de coletas para estudo de caso

\begin{tabular}{|c|c|}
\hline $\begin{array}{l}\text { Tipos de } \\
\text { Evidências }\end{array}$ & Fontes de Evidências \\
\hline Documentos & $\begin{array}{l}\text { "Lei 10.097, de } 19 \text { de dezembro de } 2000 \text { (Lei da Aprendizagem) } \\
\text { "Decreto n }{ }^{\circ} 5.598 \text {, de } 01 \text { de dezembro de 2005; } \\
\text { "Portaria n } 723 \text {, de } 23 \text { de abril de 2012; } \\
\text { "Cadastro Nacional de Aprendizagem Profissional - CNAP; } \\
\text { "Lei Complementar N } 37 \text {, de } 26 \text { de novembro de } 2003 \text { (institui o Fundo Estadual de } \\
\text { Combate a Pobreza); } \\
\text { "Anuário do Sistema Público de Emprego, Trabalho e Renda realizado pelo } \\
\text { Departamento Intersindical de Estatística e Estudos Socioeconômicos (DIEESE) em } \\
\text { 2010/2011; } \\
\text { "Pesquisa Avaliação Externa e Acompanhamento de Egressos do Projeto Primeiro } \\
\text { Passo - Jovem Aprendiz (Fundação Cearense de Pesquisa e Cultura) }\end{array}$ \\
\hline & $\begin{array}{l}\text { *PPA } 2011 \text { - } 2015 \text { do Governo do Estado; } \\
\text { "Planejamento Estratégico Secretaria do Trabalho e Desenvolvimento Social em }\end{array}$ \\
\hline
\end{tabular}




\begin{tabular}{|c|l|}
\hline $\begin{array}{c}\text { Registros de } \\
\text { arquivos }\end{array}$ & $\begin{array}{l}\text { "E13; } \\
\text { "Edital da Chamada Pública STDS no01/2012 (Edital de Credenciamento e Seleção } \\
\text { Pública para a Contratação de Instituições Executoras de QSP Financiadas pela } \\
\text { STDS); } \\
\text { "Exemplares dos livretos do curso de Assistente Administrativo. }\end{array}$ \\
\hline \multirow{3}{*}{ Entrevistas } & $\begin{array}{l}\text { Entrevistas com: } \\
\text {-Orientador da Célula de Educação Social e Profissional (CESP) da STDS; } \\
\text { - Coordenador Administrativo do Centro Comunitário Santa Maria (CCSM), umas } \\
\text { das instituições executoras contratadas; } \\
\text { - Coordenadora Pedagógica do CCSM }\end{array}$ \\
\hline
\end{tabular}

Fonte: Elaboração própria do autor

Dentre estas três fontes de evidências a primeira e a segunda se efetivaram pelo levantamento de documentos oficiais (devidamente publicados em diário oficial ou adquiridos através de solicitação formal aos gestores institucionais do projeto), leitura, e descrição das informações relevantes para identificação nestes documentos de conteúdos que se aproximam das categorias de análise escolhidas.

A terceira fonte de evidências, as entrevistas, merece melhor explicação acerca a metodologia empregada. As entrevistas representaram um importante método para coleta de dados para que possamos absorver informações que permeiam o planejamento, operação e resultados esperados na realização do Projeto Primeiro Passo - Jovem Aprendiz. Os informantes escolhidos se referem à necessidade de compreender sobre estes critérios numa perspectiva gerencial. Para tanto escolhemos entrevistar um gestor do projeto por parte da STDS e dois gestores de uma das instituições executoras contratadas pela STDS para efetivação do projeto. As entrevistas ocorreram dentro do formato semi estruturado. Nelas o entrevistado podia explanar à vontade sobre as perspectivas pedagógicas na execução do projeto na medida em que o entrevistador ia apresentado as categorias estudadas escolhidas. As entrevistas foram gravadas em áudio e as principais argumentações foram registradas para citações.

O procedimento metodológico da pesquisa empírica através do estudo de caso buscou se aproximar dos procedimentos administrativos, fundamentos presentes no planejamento e regulamentações da política pública, operações no atendimento ao público beneficiado, conteúdo pedagógico e práticas didáticas. Acreditamos que a análise destas características é capaz de nos indicar acerca os pressupostos educacionais 
priorizados na formulação, execução e objetivos dos cursos de formação inicial e continuada de trabalhadores efetivados pelo projeto pesquisado. A seguir apresentamos com mais detalhes as categorias de análise escolhidas

Financiamento, formulação e execução do projeto. Com diretrizes de fomento a geração de emprego e renda, bem como de atividades sócio econômicas através de processos de aprendizagem a STDS coordena projetos de educação social e profissional em todos os 184 municípios cearenses. Diferentes projetos, com metodologias distintas, mas com implementação e operacionalização centralizada nas regulamentações do fundo de investimento específico - na maioria dos casos o Fundo Estadual de Combate a Pobreza (FECOP) -, além de diretrizes de planejamento do próprio Governo Estadual e do MTE. “O FECOP tem como orientação principal o combate à pobreza a partir da criação de meios para o fortalecimento do patrimônio individual e social das pessoas economicamente vulneráveis” (site GABGOV/CE).

Se abordamos esta categoria de análise segundo a ótica das duas perspectivas pedagógicas da educação voltada para o trabalho apresentadas no início do artigo, verificaremos indícios que denotam a coexistência de ambas perspectivas no conjunto de demandas sociais e econômicas as quais o Projeto Primeiro Passo Jovem Aprendiz vem responder. Afirmamos isso porque, por um lado, um dos principais motivos do projeto está na qualificação profissional de curta duração para inserção no mercado de trabalho, repassando para os beneficiados conhecimentos técnicos e comportamentais que favoreçam a empregabilidade e geração de emprego e renda (assumindo assim características condizentes à perspectiva pedagógica instrumental e funcionalista). Por outro lado o projeto em análise consiste numa política pública inclusiva e de educação social básica que permite o acesso democrático (respeitando diretrizes constitucionais) da população à conhecimentos de maneira a capacitá-los para exercício cidadão e posicionamento crítico frente à realidade da juventude (assumindo assim também características condizente à perspectiva pedagógica humanista e emancipatória). Além disso, percebemos estar contido no atendimento realizado pelas instituições executoras do projeto o aspecto politicamente inclusivo de obrigatoriedade pela oferta de transporte, lanche diário, fardamento e material 
didático para os alunos atendidos de maneira a garantir boas condições físicas e humanas para a qualidade do ensino.

Diretrizes regulamentares. O Projeto Primeiro Passo é composto por três linhas de ação: Estagiário, Bolsista e Aprendiz. As linhas Bolsista e Estagiário são completamente direcionadas pelos padrões técnicos advindos da experiência administrativa com qualificação social profissional por parte da Célula de Educação Social e Profissional da STDS, "são frutos da adaptação das políticas de trabalho às demandas das prefeituras municipais e mercado de trabalho” (Gestor da CESP). No entanto a linha de ação Aprendiz (foco de nosso estudo empírico) é também, e principalmente, regulada por legislação federal. Neste sentido tanto a empresa contratante dos serviços de aprendiz como a instituição qualificadora devem respeitar os parâmetros legais descritos, por exemplo, na Portaria n ${ }^{\circ}$ 723, de 23 de abril de 2012 e na Lei 10.097, de 19 de dezembro de 2000:

Contrato de aprendizagem é o contrato de trabalho especial, ajustado por escrito e por prazo determinado, em que o empregador se compromete a assegurar ao maior de quatorze e menor de vinte e quatro anos, inscrito em programa de aprendizagem, formação técnico-profissional metódica, compatível com o seu desenvolvimento físico, moral e psicológico, e o aprendiz, a executar, com zelo e diligência, as tarefas necessárias a essa formação. (Artigo 428)

Mais uma vez podemos verificar nesta categoria de análise a coexistência das duas perspectivas pedagógicas condizentes à educação para o trabalho sob influências da ideologia liberalista. Esta dualidade de perspectivas marca a Constituição Federal brasileira no que diz respeito à educação (como já comentamos anteriormente), bem como caracteriza a Lei da Aprendizagem quando esta determina que no contrato de aprendizagem deve prevalecer o acesso à "formação técnica e profissional aliada ao desenvolvimento físico, moral e psicológico do aprendiz” (Lei 10.097, de 19 de dezembro de 2000, Artigo $1^{\circ}$ ). Outra observação acerca à dualidade das perspectivas pedagógicas estudadas no aspecto regulamentar do projeto em análise pode ser apreendida quando percebemos que um grande fator motivador para a aplicação da Lei da Aprendizagem está na possibilidade das empresas em absorver mão de obra barata para realização de serviços básicos (prevalecendo aí uma iniciativa 
voltada para empregabilidade), aliada à possibilidade de receber incentivo fiscal proveniente do abatimento no Imposto de Renda anual.

Público alvo, objetivos e metas. Tendo em vista a evidente relação entre o nível de escolaridade e oportunidades de inserção no mercado de trabalho, vemos que, segundo um estudo do Departamento Intersindical de Estatística e Estudos Socioeconômicos (DIEESE) em 2011, no Brasil atualmente 62,5\% dos empregos formais estão ocupados por indivíduos com, no mínimo, o Ensino Médio. Surge, então, a necessidade de programas de qualificação profissional como política de educação profissional e de fomento ao emprego e renda. Tais programas devem ter como objetivo, além da aprendizagem de atividades inerentes às funções específicas, a elevação da escolaridade e/ou estímulo ao (re)ingresso dos indivíduos no ensino formal.

O Projeto Primeiro Passo - Jovem Aprendiz é uma ação do Governo do Estado do Ceará que busca minimizar este quadro de vulnerabilidade que marca a mão de obra jovem e sem experiência. O público alvo deste projeto é composto por jovens de 16 a 22 anos de idade, oriundos de escola pública e que estejam cursando (ou tenham concluído a menos de 2 anos) o Ensino Médio regular. De acordo com o gestor da CESP, além das exigidas no Termo de Referência preceptor do convênio celebrado com as instituições contratadas para execução, são metas para a execução do programa: chegar ao término do curso com no máximo $10 \%$ de evasão de alunos; estimular que as empresas parceiras (onde os aprendizes exercem o estudo prático) efetivem por meio de contratação formal um mínimo 10\% do total de aprendizes beneficiados a cada ano/versão do projeto; contribuir para o avanço da escolaridade dos jovens atendidos; e contribuir para que os aprendizes superem dois obstáculos para sua inserção produtiva, ou se, a falta de experiência prévia e a falta de qualificação profissional.

Nesta categoria de análise a dualidade das perspectivas pedagógicas em estudo pode ser observada quando, primeiramente, verificamos a existência de argumentos democráticos de inclusão social através da educação profissional voltada para o público jovem (16 a 22 anos), oriundos da escola pública e que tenham 
concluído apenas o Ensino Fundamental. Os jovens nesta situação passam a ser considerados como vulneráveis às condições de precaridade e flexibilidade do mercado de trabalho, portanto detentores do direito à educação social e profissional com fins na inserção produtiva, elevação da escolaridade e amadurecimento da atividade ética e cidadã - objetivos claramente próximos a uma perspectiva pedagógica humanista e emancipatória. Ao mesmo modo, verificamos dentre os objetivos do projeto a existência de motivações econômicas na necessidade de resposta às demandas do mercado de trabalho para o cumprimento das metas. Estas diretrizes estão mais próximas à perspectiva pedagógica instrumental e funcionalista e influenciam diretamente nas operações gerenciais desta política pública quando, por exemplo, a escolha das modalidades dos cursos profissionalizantes são direcionadas exclusivamente à capacitação de pessoas para assumir vagas de trabalho em ocupações demandadas pelas empresas parceiras.

Distribuição da carga horária. A carga horária do Programa Primeiro Passo - Jovem Aprendiz também respeita a regulamentação do MTE. Esta sofreu adequações para o ano de 2012 e foi alvo de muitas críticas por parte dos professores e gestores das instituições executoras. Desde o ano 2000, com promulgação da Lei ${ }^{\circ}$ 10.097 (Lei do Aprendiz), o aluno aprendiz deve cumprir carga horária de 400 horas aulas teórica em sala de aula e 880 horas prática no espaço de trabalho da empresa parceira. No entanto a Portaria MTE $n^{\circ}$ 723, de 23 de abril de 2012 traz uma novidade que é a distribuição do cronograma letivo. Esta deve acontecer de forma que as 80 horas iniciais do curso são dedicadas exclusivamente à formação teórica e são realizadas de forma sequencial em (20 encontros, 5 dias por semana e 4 horas diárias por encontro). Nesta carga horária inicial acontecem os módulo temáticos mais básicos como higiene pessoal, direitos do trabalhador, ética e cidadania. As 1200 horas restantes (320 teóricas +880 práticas) são distribuídas de forma concomitante sendo a parte teórica com 4 horas semanais e 16 mensais (240 horas). Para cumprimento das 80 horas restantes são realizados mais 20 encontros de 4 horas ao longo dos 15 meses. Já a parte prática se efetiva com 4 horas por dia, 16 horas semanais, 64 horas mensais e 880 horas em 15 meses. As críticas ao novo modelo de organização da carga horária se referem a distancia que se estabelece entre o professor 
e seus alunos, já que estes se encontram apenas uma vez por semana na maior parte do curso. Argumenta-se que o aluno passa a pouco valorizar as atividades de ensino em detrimento ao trabalho realizado na empresa.

Conteúdo Programático. Na execução do Projeto Primeiro Passo Jovem Aprendiz há apenas duas tipologias de cursos profissionalizantes ofertados, a saber: Assistente Administrativo e Alimentador de Linha de Produção. Segundo o gestor CESP a especificidade dos cursos corresponde às demandas mais correntes das empresas ou indústrias que se tornam parceiras e solicitam aprendizes para cumprir distintas atividades administrativas de escritório ou atividades básicas de produção no setor fabril. A formação das turmas segundo a tipologia do curso respeita critérios como interesse do aluno, município ou região onde a turma acontece, além de demandas das empresas parceiras por mão de obra aprendiz.

Quanto ao conteúdo programático dos cursos existe uma padronização estabelecida pela STDS. As apostilas foram elaboradas de acordo com os 22 módulos temáticos de cada curso. A instituição executora recebe o arquivo da apostila, replicao e distribui dentre os alunos beneficiados. "O material é ilustrativo e de linguagem direcionada aos jovens. Possui conteúdo à fortalecer a relação entre o professor com a turma, com atividades de sala de aula, desafios de interpretação, trabalhos de grupo e situações problemas para resolução", afirma o gestor administrativo do CCSM.

Verificamos que segundo o Artigo 10 da Portaria No 723/2012 do MTE a profissionalização realizada através da Lei da Aprendizagem assume a metodologia (anteriormente desenvolvida pelo Plano Nacional de Qualificação - PNQ) da Qualificação Social e Profissional - QSP onde, necessariamente, são consideradas diretrizes gerais, diretrizes curriculares e conteúdos de formação bumana e científica devidamente contextualizados. Sendo assim, os 22 módulos temáticos desenvolvidos para o ensino do conteúdo programático são organizados e distribuídos de forma a respeitar estas diretrizes estabelecidas pela referida Portaria.

A organização dos 22 módulos temáticos passa também pela divisão entre conhecimentos de ordem geral e formação humana e científica (aqueles mais associados ao aspecto da qualificação social - ou seja, da tendência educacional 
humanista e emancipatória), e conhecimentos de ordem específica, relacionada ao conteúdo próprio da ocupação a qual se está estudando (aqueles mais associados ao aspecto da qualificação profissional - ou seja, da tendência educacional funcionalista e instrumental de acordo com nossa fundamentação teórica).

Podemos identificar no curso de Assistente Administrativo (o qual representa mais de $80 \%$ das turmas abertas pelo Projeto Primeiro Passo - Jovem Aprendiz no ano de 2014) os seguintes módulos relacionados à perspectiva pedagógica humanista e emancipatória: Introdução à Aprendizagem (80h/a); Comunicação Oral e Escrita (32h/a); Educaşão para o Consumo (12h/a);Cidadania e Educação Fiscal (8h/a); Saúde Sexual, Direitos Sexuais e Reprodutivos e Relações de Gênero (8h/a); Formas Alternativas de Trabalho e Renda com Enfoque na Juventude (12h/a); Informações sobre Mercado e Mundo do Trabalho e Trabalho em Equipe (20h/a); Organização, Planejamento e Controle do Processo de Trabalho (12h/a); Saúde e Segurança no Trabalho (12h/a); Direitos Trabalhistas e Previdenciários (8h/a); Uso Indevido do Álcool, Tabaco e Outros (8h/a); Preservação do Equilíbrio do Meio Ambiente (8h/a); e Diversidade Cultural Relacionada ao Mundo do Trabalbo (8h/a).

Já sobre os módulos relacionados à perspectiva pedagógica funcionalista e instrumental podemos indicar: A Empresa no mundo globalizado (20h/a);Funções, Atribuições e Responsabilidades do Assistente Administrativo (20h/a); Qualidade na Prestação de Serviços Administrativos (20h/a); Assistente Administrativo: competências pessoais e comunicativas (20h/a); As Finanças na Empresa (20h/a).

\subsection{A Dualidadde de Perspectivas Pedagógicas na Execução do Projeto Primeiro Passo - Jovem Aprendiz}

As informação apresentadas até o momento sobre o projeto em questão podem nos dar indícios sobre como acontece a coexistência das duas perspectivas pedagógicas estudas: uma instrumental e funcionalista, outra humanista e emancipatória. Os dados obtidos através das categorias de análise escolhidas permitem analisar sobre ambas perspectivas pedagógicas na execução dos cursos de formação inicial e continuada no âmbito do Projeto Primeiro Passo - Jovem Aprendiz. 
Primeiramente, se contabilizarmos a quantidade de horas aulas que envolvem conteúdos relacionados à tendência educacional humanista e emancipatória chegaremos ao valor de 112 horas aulas, ou seja, 28\% do total de 400 horas aulas reservados para as atividades teóricas do curso de Assistente Administrativo. Observamos também que a quantidade horas reservadas para elevação da escolaridade é de 84 horas aulas. Tendo em vista que a elevação da escolaridade se aproxima mais de uma tendência educacional focada no auto aprimoramento do sujeito podemos somar estas 84 horas com as 112 horas identificadas anteriormente para demarcar a quantidade de horas reservadas ao ensino de "competências sociais" (MARKERT 2004, 193). Neste caso teremos 196 horas aulas, ou seja, 49\% do total de horas teóricas.

Para construir indicadores capazes de avaliar a execução dos cursos deste projeto a STDS fechou convênio com a Fundação Cearense de Pesquisa e Cultura (FCPC) para realização de um estudo para avaliação externa de suas ações de profissionalização. Os dados deste estudo estão apresentados no documento Avaliação Externa e Acompanhamento de Egressos das Ações de QSP Financiadas pela STDS (2014). Segundo este estudo o projeto (em sua dimensão de execução à nível de todo o estado do Ceará) é avaliado pelos alunos predominantemente como "bom” e “ótimo" nas perguntas que tratam sobre a qualidade do ensino de acordo com aspectos de uma perspectiva pedagógica humanista e emancipatória, tais como: melhoria da escrita, leitura e comunicação pessoal (verbal e não verbal); avanço nos conhecimento de informática; ampliação da noção de cidadania, direitos trabalhistas e humanos, cidadania e diversidade cultural.

Em relação à perspectiva pedagógica instrumental e funcionalista, se contabilizarmos a quantidade de horas aulas que envolvem conteúdos relacionados à tendência educacional funcionalista e instrumental chegaremos ao valor de 204 horas aulas, ou seja, $51 \%$ do total de 400 horas aulas reservados para as atividades teóricas do curso de Assistente Administrativo.

Há, no entanto, um grande diferencial quando queremos analisar a perspectiva educacional relacionada à empregabilidade no Projeto Primeiro Passo - 
Jovem Aprendiz, e este diferencial são as atividades que são desenvolvidas no momento fora da sala de aula, trata-se da própria condição de aprendiz dos alunos participantes do projeto. Sendo assim estes jovens devem cumprir carga horária semanal de 16 horas, no mínimo, em alguma empresa parceira do projeto exercendo atividades de trabalho condizentes com o curso que frequentam, no caso da nossa pesquisa, com o curso de Assistente Administrativo. É notário a grande prioridade de carga horária que é dada a esta experiência dos alunos nas empresas. Como já podemos verificar, num total de 1200 horas de execução do projeto, 400 horas são para as atividades teóricas de sala de aula e 800 horas são destinadas às atividades práticas nas empresas. O exercício de funções na condição de aprendizes consiste, portanto, em $66,6 \%$ do total de horas que os alunos devem cumprir para obter certificação do projeto.

Nas entrevistas e observações de campo realizadas é fato que a permanência dos aprendizes na empresa após o término do curso demonstra-se ser o principal objetivo perseguido pelas equipes de execução. Ou seja, a garantia da empregabilidade dos aprendizes é o principal meio pelo qual os resultados do projeto serão avaliados por parte do Órgão Financiador. De acordo com mesmo estudo de avaliação externa realizado pela FCPC (2014) é possível afirmar que, em termos absolutos, a cada cem jovens inseridos na condição de aprendiz, quinze conseguiram permanecer com vínculo formal de trabalho na empresa que exerceram a aprendizagem, dezesseis conseguiram inserção formal em outra empresa, e doze conseguiram algum tipo de ocupação através de vínculos laborais tradicionalmente mais vulneráveis, como o assalariamento sem carteira ou trabalho autônomo. As estatística desta pesquisa demonstram que o percentual de inserção produtiva dos alunos pesquisados após cinco meses do período de aprendizagem é de $31 \%$ se considerarmos apenas os vínculos formais de emprego e de $41,5 \%$ se somarmos a este os tipos de vinculações informais que compõem o mundo do trabalho. Destacamos ainda que dos $58,5 \%$ ex-alunos que não estavam trabalhando no momento da entrevista $17 \%$ deles já haviam exercido algum tipo de trabalho após o término do curso. Outro dado animador está no fato de que, daqueles jovens que já tinham trabalhado após o término do curso (58\%), 51,4\% afirmaram utilizaram os 
conhecimentos adquiridos na qualificação profissional para o exercício do serviço. Estes dados são apresentados pelos entrevistados como panorama de êxito por parte da execução do Projeto Primeiro Passo - Linha Aprendiz.

\section{CONSIDERAÇÕES FINAIS}

A motivação por compreender sobre aspectos pedagógicos presentes nas políticas públicas de educação profissional está na possibilidade de analisarmos os pressupostos fundamentais para ações públicas de profissionalização com foco na geração de renda, desenvolvimento econômico e social. Na necessidade de focar nosso estudo, concentramos nossas análises em cursos de formação inicial e continuada de trabalhadores.

As transformações tecnológicas do último século são acompanhadas pelo formato de organização da educação aplicada às demandas do mundo do trabalho. Neste cenário as diretrizes liberais de racionalização da produção, acumulação de capital, livre concorrência e flexibilização nas contratações de pessoal reforçam ainda mais o reconhecimento da educação profissional como fator de entrada e permanência no mercado de trabalho.

Como foi visto, há referências aos fundamentos liberais para a educação na Constituição Federal de 1988 ao revelar que o papel do ensino é promover o pleno desenvolvimento do indivíduo e sua qualificação para o trabalho. Observamos já aí a coexistência da dualidade de pressupostos pedagógicos identificados e discutidos conceitualmente no início do artigo, ou seja, uma perspectiva educacional humanistaemancipatória e outra funcionalista-instrumental.

A coexistência de ambas tendências é ainda percebida quando observamos que nas últimas décadas as ações do Estado brasileiro voltadas para educação profissional tomam como prerrogativa a necessidade por ampliar a empregabilidade do público atendido, ou seja, sua capacidade técnica para inserção produtiva. Por outro lado, o movimento de organização democrática, o qual vem se desdobrando no Brasil desde 1988, traduz-se como conquistas no âmbito da educação profissional na medida em que passa a ser exigência a inclusão nos currículos de conteúdos 
relacionados a formação integral do sujeito, ações específicas para o público jovem e estímulo à participação cidadã.

Duran te o estudo empírico realizamos análises a partir de documentos oficiais, observações de campo e entrevistas com gestores do Projeto Primeiro Passo Jovem Aprendiz e verificamos a coexistência das duas perspectivas pedagógicas na execução desta ação. Observa-se que o projeto respeita as considerações regulamentares da Qualificação Social e Profissional (QSP) - metodologia implantada pelo MTE desde a criação do Plano Nacional de Qualificação (PNQ) em 2003 -, buscando equilibrar o ensino de conhecimentos do âmbito político e humano-social com o ensino de normas e técnicas destinadas à empregabilidade dos alunos beneficiados.

A carga horária do projeto pesquisado conduz atividades teóricas no sentido de equilibrar ambos pressupostos liberais da educação para o trabalho. Ou seja, assim como os programas PNQ e Projovem Integrado, a Lei Aprendizagem regimento que prescreve o a linha aprendiz do Projeto Primeiro Passo - em suas atividades de sala de aula a complementariedade do ensino profissionalizante com conteúdos de ordem a fortalecer valores éticos que posicionem o aluno como sujeito de direitos e deveres na organização social e em constante transformação e equilíbrio.

No entanto se observarmos a carga horária das atividades práticas perceberemos a extrema predominância do estímulo à empregabilidade através do trabalho nas empresas parceiras, onde os aprendizes aplicam o saber instrumentalizado e funcional adquirido em sala de aula. A ênfase da perspectiva pedagógica com fins na conquista ou manutenção do emprego é percebida também nas conversas com o corpo técnico responsável pelo planejamento, execução e monitoramento do projeto. $\mathrm{O}$ resultado de inserção produtiva de $41,5 \%$ dos alunos egressos (somando a colocação formal com a informal em qualquer empresa após o término do curso) é apontado pelos três gestores entrevistados como fator de incentivo para a continuidade dos trabalhos.

A prerrogativa educacional voltada prioritariamente para o mercado de trabalho parece ser uma marca crescente no âmbito das políticas públicas de formação 
inicial e continuada (FIC) no Brasil. A exemplo disso observamos a pouca observação da perspectiva pedagógica humanista e emancipatória na regulamentação e currículo dos cursos FIC vinculados ao Programa Nacional de Acesso ao Ensino Técnico e Emprego (PRONATEC). A atenção parece estar no ensino de unidirecional ao ensino de competências que favoreçam a autonomia do sujeito em busca seu espaço no mercado, sua sagacidade pelo melhor desempenho, capacidade de gestão, a primazia do conhecimento individual, do acesso à informação, a capacidade de apresentar respostas rápidas e criativas aos problemas do dia a dia, enfim, a educação para o trabalho parece, cada vez mais, assumir como fator de destaque individual as qualificações técnicas para que o sujeito consiga construir sua história de vida profissional.

\section{BIBLIOGRAFIA}

ANTUNES, Ricardo L. C. O Caracol e Sua Concha: Ensaios Sobre a Nova Morfologia do Trabalho - São Paulo: Boitempo, 2005

DIEESE. Anuário do Sistema Público de Emprego, Trabalho e Renda 2010/2011: qualificação social e profissional. 3. ed. - São Paulo: DIEESE, 2011.

FUNDAÇÃO CEARENSE DE PESQUISA E CULTURA (FCPC). Avaliação Externa e Acompanhamento de Egressos do Projeto Primeiro Passo Aprendiz. Fortaleza: Editora Bussola, 2014. Disponível em: http:// www.projetotrabalhoemfoco.com/.

MARKERT, Werner (org.) . Teorias de educação do iluminismo, conceitos de trabalho e sujeito: contribuições para uma teoria crítica da formação do homem. Werner Markert (org.). Rio de Janeiro: Tempo Brasileio, 1994. 